\title{
NOTE
}

\section{Carbon isotope fractionation by a marine diatom: dependence on the growth-rate-limiting resource}

\author{
Ulf Riebesell*, Steffen Burkhardt, Anke Dauelsberg, Bernd Kroon
}

Alfred Wegener Institute for Polar and Marine Research, Postfach 1201 61, 27515 Bremerhaven, Germany

\begin{abstract}
The large temporal and spatial variability in carbon isotope fractionation of marine phytoplankton $\left(\varepsilon_{p}\right)$ is thought to reflect differences in environmental conditions. Meaningful interpretation of this variability requires an understanding of the processes responsible for phytoplankton isotope fractionation. While numerous factors have been suggested to potentially influence $\varepsilon_{\mathrm{p}}$, recent theoretical and experimental evidence has emphasized the primary role of phytoplankton growth rate $(\mu)$ and $\mathrm{CO}_{2}$ concentration ( $\left(\mathrm{CO}_{2} \mathrm{aq}\right]$ ) in controlling $\varepsilon_{\mathrm{p}}$. Experimental examination of the relationship of $\varepsilon_{\mathrm{p}}$ with $\mu$ and $\left[\mathrm{CO}_{2} \mathrm{aq}\right]$ in studies using different experimental approaches, however, has yielded inconsistent results. Here we directly compare new and previously published data on $\varepsilon_{\mathrm{p}}$ as a function of $\mathrm{CO}_{2}$ concentration and growth rate for the marine diatom Phaeodactylum tricornutum. When grown under nitrogen-deficient conditions (nitrate-limited chemostat), $\varepsilon_{\mathrm{p}}$ of $P$. tricornutum decreases with increasing growth rate. In contrast, under $\mathrm{N}$-replete conditions $\varepsilon_{\mathrm{p}}$ values are considerably lower at comparable growth rates and $\mathrm{CO}_{2}$ concentrations and are largely insensitive to a 3 -fold increase in growth rate due to increasing photon flux density. In both experimental approaches, $\varepsilon_{\mathrm{p}}$ shows a relatively small $\mathrm{CO}_{2}$ sensitivity in the range of $\mathrm{CO}_{2}$ concentrations naturally occurring in the ocean ( 8 to $25 \mu \mathrm{mol} \mathrm{kg}{ }^{-1}$ ). Below ca $5 \mu \mathrm{mol} \mathrm{CO}_{2} \mathrm{~kg}^{-1}$, a strong decline in $\varepsilon_{\mathrm{p}}$ with decreasing $\left[\mathrm{CO}_{2} \mathrm{aq}\right]$ is observed. The apparent difference in $\varepsilon_{\mathrm{p}}$ responses between nitrate-limited and light-controlled cultures of $P$. tricornutum suggests a principal difference in carbon acquisition for different growth-rate-limiting resources. A mechanistic explanation is proposed and potential implications for the interpretation of phytoplankton carbon isotope fractionation are discussed.
\end{abstract}

KEY WORDS: $\delta^{13} \mathrm{C} \cdot$ Isotope fractionation $\cdot \mathrm{CO}_{2} \cdot$ Phaeodactylum tricornutum $\cdot$ Growth limitation

The carbon isotopic composition $\left(\delta^{13} \mathrm{C}\right)$ of marine organic matter differs considerably from that of the dissolved inorganic carbon (DIC) from which it was

•E-mail: uriebesell@awi-bremerhaven.de formed. This difference is mainly due to the large discrimination against ${ }^{13} \mathrm{C}$ during photosynthetic carbon fixation. Large spatial and temporal variability in suspended and sedimentary organic matter $\delta^{13} \mathrm{C}$ shows that marine photosynthetic carbon isotope fractionation $\left(\varepsilon_{p}\right)$ varies in space and time, both seasonally (Fogel et al. 1992) and over geological time (Arthur et al. 1985, Jasper et al. 1994). This variability is thought to reflect differences in the environmental conditions under which the organic matter was synthesized. Understanding the mechanisms of photosynthetic carbon isotope fractionation could provide a means for reconstructing growth conditions at the time of organic matter production.

One of the main factors considered to be responsible for the observed variability in phytoplankton carbon isotope fractionation is the concentration of dissolved $\mathrm{CO}_{2}$ ([CO $\left.\mathrm{CO}_{2} \mathrm{aq}\right] ;$ Deuser et al. 1968, Mizutani \& Wada 1982, Rau et al. 1989). Experimental evidence for a dependence of $\varepsilon_{\mathrm{p}}$ on $\left[\mathrm{CO}_{2} \mathrm{aq}\right]$ in marine phytoplankton was first provided by Degens et al. (1968). More recently, based on theoretical considerations it has been pointed out that $\varepsilon_{\mathrm{p}}$ is ultimately determined by the ratio of cellular carbon fixation to carbon flux into the cell (Francois et al. 1993, Goericke et al. 1994). With carbon fixation corresponding to the product of cellular carbon content and specific growth rate, and carbon flux related to $\left[\mathrm{CO}_{2} \mathrm{aq}\right]$, experimental results became directly comparable to theoretical predictions (Laws et al. 1995, Rau et al. 1996)

This was substantiated by experimental results of Laws et al. (1995), who found an inverse relationship between $\varepsilon_{\mathrm{p}}$ and the ratio of algal growth rate $(\mu)$ and $\left[\mathrm{CO}_{2} \mathrm{aq}\right]\left(\mu /\left[\mathrm{CO}_{2} \mathrm{aq}\right]\right)$. Whereas subsequent experiments using the same experimental approach (i.e. chemostat cultures) have yielded compatible $\varepsilon_{p}$ responses (Bidigare et al. 1997, Laws et al. 1997, Popp et al. 1998), no clear relationships were obtained in stud- 
ies using batch culture incubations (Hinga et al. 1994, Thompson \& Calvert 1994, 1995, Johnston 1996 , Burkhardt et al. 1999a). While part of the discrepancy may be due to poorly constrained experimental conditions in batch culture incubations or species-specific differences in isotope fractionation, the principal disagreement in some of these results has remained a matter of concern. For instance, at high $\left[\mathrm{CO}_{2} \mathrm{aq}\right]$ and $\mu$, N-limited chemostat incubations have consistently yielded $\varepsilon_{p}$ values of about $25 \%$, i.e. close to isotope fractionation of the carboxylating enzyme RUBISCO (Laws et al. 1995, 1997, Bidigare et al. 1997, Popp et al. 1998). At similar [ $\mathrm{CO}_{2} \mathrm{aq}$ ] and $\mu$ in batch culture and continuous culture incubations in which $\mu$ was controlled by photon flux density (PFD), maximum isotope fractionation was found to be much lower (Hinga et al. 1994, Johnston 1996, Korb et al. 1996, Burkhardt et al. 1999a)

Confounded by the inconsistency of $\varepsilon_{\mathrm{p}}$ versus $\mu /\left[\mathrm{CO}_{2} \mathrm{aq}\right]$ relationships obtained in different studies, we have attempted to directly compare isotope fractionation data generated by the 2 approaches. Unfortunately, the use of different microalgal species or differences in the $\mu$ and $\left[\mathrm{CO}_{2} \mathrm{aq}\right]$ ranges covered in the various studies in most cases precludes direct comparison between data sets. At least for 1 species, the marine diatom Phaeodactylum tricornutum, however, $\varepsilon_{\mathrm{p}}$ has been measured at nearly identical $\mu$ and $\left[\mathrm{CO}_{2} \mathrm{aq}\right.$ ] in both chemostat (Laws et al. 1995, 1997) and batch culture experiments (Johnston 1996, Burkhardt et al. 1999a, this study). As will be shown in the following, direct comparison of these data sets reveals similarities in the general trend of $\varepsilon_{\mathrm{p}}$ with $\left[\mathrm{CO}_{2} \mathrm{aq}\right]$. Considerable differences exist in the responses of $\varepsilon_{p}$ to changes in $\mu$ as well as in the absolute values of $\varepsilon_{\mathrm{p}}$ under comparable $\mu$ and $\left[\mathrm{CO}_{2} \mathrm{aq}\right]$.

Materials and methods. Experiments: Dilute batch cultures of 2 different strains of the marine diatom Phaeodactylum tricornutum Bohlin (clone CCAP 1052/1A and CCMP 1327) were grown in 0.2 um-filtered natural seawater enriched with nitrate, silicate, phosphate, trace metals and vitamins at concentrations of $\mathrm{f} / 2$ medium (Guillard \& Ryther 1962). Depending on the batch of seawater, salinity varied between 30.5 and 31.5. Prior to the experiments, stock cultures were adapted to experimental conditions of the respective treatments for at least 9 cell divisions. A range of [CO $\mathrm{CO}_{2} \mathrm{aq}$ (0.2 to $22.4 \mu \mathrm{mol} \mathrm{kg}^{-1}$, see Table 1$)$ in the growth medium was obtained by manipulating the carbonate system through addition of $\mathrm{NaOH}$ or $\mathrm{HCl}$. This treatment changes alkalinity and $p H$ of the medium and leaves DIC approximately constant. Pre-adapted cultures were incubated in 2.41 borosilicate glass bottles, sealed with PBT-lined screw caps. The bottles were closed without headspace and cells were kept in suspension by inversion of the bottles 2 to 3 times $\mathrm{d}^{-1}$. The batch cultures were kept in Rumed 1200 lightthermostats at a temperature of $15^{\circ} \mathrm{C}$ under continuous

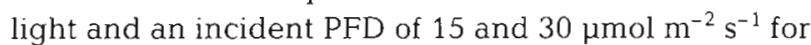
clone CCAP 1052/1A and $150 \mu \mathrm{mol} \mathrm{m} \mathrm{m}^{-2} \mathrm{~s}^{-1}$ for clone CCMP 1327. Results from these experiments are combined with those of Burkhardt et al. (1999a), who incubated $P$. tricornutum clone CCAP 1052/1A at a PFD of $150 \mu \mathrm{mol} \mathrm{m} \mathrm{m}^{-2} \mathrm{~s}^{-1}$ under continuous light and a light/dark cycle of $16 / 8 \mathrm{~h}$.

To minimize $\mathrm{pH}$ drift and associated shifts in carbon speciation as well as a change in $\delta^{13} \mathrm{C}$ of DIC $\left(\delta^{13} \mathrm{C}_{\text {DIC }}\right)$ during experimental incubations, cells in all treatments were harvested at particulate organic carbon (POC) concentrations below $50 \mu \mathrm{mol} \mathrm{kg}{ }^{-1}$. As shown by Burkhardt et al. (1999b), at POC concentrations below this level, $\mathrm{pH}$ changes of the unbuffered medium and changes in $\delta^{13} \mathrm{C}_{\mathrm{D} \mid \mathrm{C}}$ due to photosynthetic ${ }^{13} \mathrm{C}$ discrimination remained below 0.05 units and $0.4 \%$, respectively. To allow at least 8 cell divisions under experimental conditions, initial POC concentrations in the growth medium were kept below $0.1 \mu \mathrm{mol} \mathrm{kg}^{-1}$. Bacterial counts on DAPIstained samples using epifluorescence microscopy (Hobbie et al. 1977) indicated that bacterial biomass never exceeded $1 \%$ of algal biomass in the cultures and its contribution to total POC was therefore considered negligible.

Carbonate system: DIC was determined coulometrically in duplicate with a system similar to that described by Johnson et al. (1987). Total alkalinity was titrated in duplicate with an automated, temperaturecontrolled system at $20^{\circ} \mathrm{C}$, and was determined using the Gran-plot approach (Almgren et al. 1988). [CO $\mathrm{CO}_{2} \mathrm{aq}$ ] was calculated from DIC concentrations, total alkalinity, temperature, salinity, and concentrations of phosphate and silicate using dissociation constants of Goyet \& Poisson (1989).

Stable carbon isotope fractionation: Samples were filtered using precombusted $\left(500^{\circ} \mathrm{C}, 12 \mathrm{~h}\right)$ Whatman GF-C glass fiber filters. All filters were acidified with $0.1 \mathrm{~N} \mathrm{HCl}$ prior to measurements and dried for $2 \mathrm{~h}$ at $60^{\circ} \mathrm{C}$. POC concentration and $\delta^{13} \mathrm{C}_{\mathrm{POC}}$ were measured in duplicate on the same filters with a continuous flow isotope ratio mass spectrometer (Europa Scientific, ANCA SL 20-20). $\delta^{13} C_{\text {DIC }}$ was analyzed on unfiltered subsamples preserved with $\mathrm{HgCl}_{2}$ with a Finnegan MAT Delta-S mass spectrometer after acidification with $100 \% \mathrm{H}_{3} \mathrm{PO}_{4}$ at $25^{\circ} \mathrm{C}$ in a vacuum extraction line as described by Mackensen et al. (1996). The carbon isotopic composition is reported in $\delta$-notation relative to PeeDee belemnite as a standard:

$$
\delta^{13} \mathrm{C}\left[\frac{\left({ }^{13} \mathrm{C} /{ }^{12} \mathrm{C}\right) \text { sample }}{\left({ }^{13} \mathrm{C} /{ }^{12} \mathrm{C}\right) \text { standard }}-1\right] 1000
$$


The isotopic composition of dissolved molecular $\mathrm{CO}_{2}$ $\left(\delta^{13} \mathrm{C}_{\mathrm{CO} 2}\right)$ was calculated from $\delta^{13} \mathrm{C}_{\text {DIC }}$ following the equation provided by Rau et al. (1996) based on Mook et al. (1974):

$$
\delta^{13} \mathrm{C}_{\mathrm{CO}_{2}}=\delta^{13} \mathrm{C}_{\mathrm{DIC}}+23.644-\frac{9701.5}{T_{\mathrm{K}}}
$$

where $T_{\mathrm{K}}$ is the absolute temperature in Kelvin.

The isotope fractionation associated with photosynthetic $\mathrm{CO}_{2}$ fixation, $\varepsilon_{\mathrm{p}}$, was calculated relative to the isotopic composition of $\mathrm{CO}_{2}$ in the bulk medium according to Freeman \& Hayes (1992):

$$
\varepsilon_{\mathrm{p}}=\frac{\delta^{13} \mathrm{C}_{\mathrm{CO}_{2}}-\delta^{13} \mathrm{C}_{\mathrm{POC}}}{1+\delta^{13} \mathrm{C}_{\mathrm{POC}} / 1000}
$$

Growth rates: Cell concentrations of Phaeodactylum tricornutum were determined with a Coulter 'Multisizer' on duplicate $20 \mathrm{ml}$ subsamples, preserved with Lugol's iodine (Edler 1979). Average $24 \mathrm{~h}$ growth rates $\left(\mu_{L+D}\right)$ were calculated from daily changes in cell concentration according to

$$
\mu_{L+D}=\frac{\ln N_{1}-\ln N_{0}}{\Delta t}
$$

where $N_{0}$ and $N_{1}$ are cell concentrations at the beginning and the end of the time interval $\Delta t$. During incubations, cell numbers were determined daily for at least $3 \mathrm{~d}$ in control bottles run in parallel to each experimental set-up. No subsamples were taken from the experimental vessels during incubations to avoid disturbance of the closed system, but cell concentrations were determined before and after incubation and $\mu$ calculated from these were compared to those in the control bottles. The cellular carbon content was derived from measurements of $\mathrm{POC}$ and cell concentration.

Photosynthetic carbon isotope fractionation mainly occurs through enzymatic $\mathrm{CO}_{2}$ fixation during the photoperiod. Thus, to account for differences in the photoperiodic length (16/8 h light/dark cycle vs continuous light), instantaneous growth rates $\left(\mu_{1}\right)$ were calculated according to

$$
\mu_{i}=\frac{(L+D) \mu_{L+D}}{L-D_{r}}
$$

where $L$ and $D$ are the lengths of the light and dark periods, respectively, and $r$ accounts for respiratory carbon loss during the dark period. The latter was assumed to be 0.15 (Laws \& Bannister 1980).

Data comparison: Results obtained in this investigation and in the work of Burkhardt et al. (1999a) are directly comparable with earlier work on $\varepsilon_{\mathrm{p}}$ of Phaeodactylum tricornutum in relation to $\mu$ and $\left[\mathrm{CO}_{2} \mathrm{aq}\right]$ by Laws et al. (1995, 1997) and Johnston (1996). These investigators used $P$. tricornutum clones CCMP 1327 (Laws et al. 1995, 1997) and CCAP 1052/1A (Johnston 1996), i.e. the same 2 strains grown in this study. Experiments were performed in (1) nitrate-limited, light-saturated chemostat cultures (Laws et al. 1995, 1997), and (2) nutrient-replete batch culture incubations under variable light conditions (Johnston 1996, Burkhardt et al. 1999a, this study). Thus, the main difference between the experimental set-ups is the factor which controls algal growth rate, i.e. the rate of nutrient supply in approach 1 versus PFD in approach 2.

To allow direct comparison of the data sets, it was necessary to convert some of the data to yield identical units. Cell doubling rates reported by Johnston (1996) were transformed to specific $\mu$ by multiplying with $\ln 2$. Differences between the studies also exist with respect to the light/dark cycle. Whereas incubations by Johnston (1996) and in part by Burkhardt et al. (1999a) were conducted at a light/dark cycle of $16 / 8 \mathrm{~h}$, all other experiments were performed under continuous light. To account for this difference, $\mu_{1}$, i.e. $\mu$ during the photoperiod (see above), was used for data comparison. $\left[\mathrm{CO}_{2} \mathrm{aq}\right]$ for the data of Johnston (1996) was calculated assuming temperature, salinity, nutrient concentrations $(\mathrm{P}, \mathrm{Si})$, and $\mathrm{pH}$ as given in the paper and a $\mathrm{pCO}_{2}$ value of $360 \mathrm{ppm}$ (medium continuously bubbled with air). This yielded a value of $11.7 \mu \mathrm{mol} \mathrm{CO}_{2} \mathrm{~kg}^{-1}$ $\varepsilon_{p}$ was calculated from $\delta^{13} \mathrm{C}_{\text {POC }}$ presented in Johnston (1996) according to Eq. (3) assuming $\delta^{13} \mathrm{C}_{\mathrm{CO}_{2}}$ to equal $-9.06 \%$. The latter was calculated from the $\delta^{13} \mathrm{C}$ of the air bubbled through the medium, measured to be $-7.98 \%$ (Johnston 1996), and an equilibrium fractionation between gaseous and dissolved $\mathrm{CO}_{2}$ as given by Mook (1986).

In order to directly compare $\varepsilon_{p}$ as a function of $\left[\mathrm{CO}_{2} \mathrm{aq}\right]$ between the different data sets, we grouped the available data into 3 categories according to $\mu_{\mathrm{j}}$ : (1) low growth rates, $\mu_{\mathrm{i}}=0.5 \mathrm{~d}^{-1} \pm 10 \%$ (2) intermediate growth rates, $\mu_{1}=1.0 \mathrm{~d}^{-1} \pm 10 \%$, and (3) high growth rates, $\mu_{1}=1.5 \mathrm{~d}^{-1} \pm 10 \%$

All data used in the comparison, including data obtained in this study, are listed in Table 1. Data obtained at $\mu_{\mathrm{i}}$ outside these relatively narrow ranges are listed separately (Table 2; open symbols in Fig. 1). This includes data measured at a PFD of $150 \mu \mathrm{mol} \mathrm{m}{ }^{-2}$ $\mathrm{s}^{-1}$ and a light/dark cycle of $16 / 8 \mathrm{~h}$ (Burkhardt et al. 1999a). Although 24 h average growth rate were similar to those obtained in parallel experiments under continuous light, $\mu_{\mathrm{i}}$ calculated according to Eq. (5) were significantly higher in 16/8 h light/dark cycle incubations than the range given in Category $\mathrm{C}$ (see Table 2). As discussed in detail in Burkhardt et al. (1999a), the difference in the light/dark cycle had no effect on the isotope fractionation of Phaeodactylum tricornutum (Fig. 1C). 
Table 1. Experimental results for Phaeodactylum tricornutum from various studies obtained in nitrate-limited chemostats (Laws et al. 1997) and light-controlled batch culture incubations (Johnston 1996, Burkhardt et al. 1999a, this study)i ${ }^{*}$ and ${ }^{\prime}$ denote the use of strains CCMP 1327 and CCAP 1052/1A, respectively

\begin{tabular}{|c|c|c|c|c|c|c|c|}
\hline$\underset{\left(\mu \mathrm{mol} \mathrm{kg}^{-1}\right)}{\left[\mathrm{CO}_{2} \mathrm{aq}\right]}$ & $\mathrm{pH}$ & $\begin{array}{c}\text { DIC } \\
\left(\mathrm{mmol} \mathrm{kg}^{-1}\right)\end{array}$ & $\begin{array}{c}\mu_{\mathrm{i}} \\
\left(\mathrm{d}^{-1}\right)\end{array}$ & $\begin{array}{c}\delta^{13} \mathrm{C}_{\text {poC }} \\
(\%)\end{array}$ & $\begin{array}{c}\varepsilon_{\mathrm{p}} \\
(\%)\end{array}$ & $\begin{array}{c}\mathrm{C} / \text { cell } \\
\left(\mathrm{pg} \text { cell }^{-1}\right)\end{array}$ & Source \\
\hline \multicolumn{8}{|c|}{ (A) Low growth rates } \\
\hline 34.71 & 7.67 & 2.27 & 0.50 & -40.47 & 25.72 & 6.87 & Laws et al. (1997)" \\
\hline 22.23 & 7.83 & 2.17 & 0.50 & -47.70 & 24.35 & 9.57 & \\
\hline 6.49 & 8.26 & 1.86 & 0.50 & -32.99 & 19.85 & 7.94 & \\
\hline 3.56 & 8.46 & 1.76 & 0.50 & -29.73 & 20.63 & 7.24 & \\
\hline 0.98 & 8.82 & 1.45 & 0.50 & -17.30 & 10.65 & 5.82 & \\
\hline 11.70 & 8.20 & -1.89 & 0.55 & -21.10 & 12.30 & - & Johnston (1996) ". \\
\hline 14.90 & 8.20 & 2.125 & 0.49 & -25.01 & 14.84 & 18.02 & This study ${ }^{\prime}$ \\
\hline 7.96 & 8.45 & 2.136 & 0.51 & -23.18 & 12.93 & 16.91 & \\
\hline 3.85 & 8.72 & 2.147 & 0.50 & -21.81 & 11.51 & 15.86 & \\
\hline 1.80 & 8.98 & 2.164 & 0.47 & -19.62 & 9.26 & 13.76 & \\
\hline 0.60 & 9.32 & 2.179 & 0.48 & -14.73 & 4.24 & 12.49 & \\
\hline \multicolumn{8}{|c|}{ (B) Intermediate growth rates } \\
\hline 11.98 & 8.06 & 2.05 & 1.00 & -38.10 & 20.58 & 7.53 & Laws et al. (1997) \\
\hline 0.92 & 8.82 & 1.36 & 1.04 & -20.60 & 11.08 & - & \\
\hline 11.70 & 8.20 & $\sim 1.89$ & 1.16 & -20.80 & 11.99 & - & Johnston (1996) ${ }^{*}$ \\
\hline 22.42 & 8.10 & 2.028 & 1.06 & -25.25 & 15.09 & 9.29 & This study $"$ \\
\hline 11.58 & 8.31 & 2.058 & 1.03 & -24.50 & 14.31 & 9.04 & \\
\hline 6.91 & 8.50 & 2.117 & 0.90 & -23.98 & 13.76 & 8.75 & \\
\hline 3.85 & 8.71 & 2.076 & 1.00 & -23.73 & 13.51 & 9.20 & \\
\hline 2.79 & 8.83 & 2.065 & 1.02 & -20.14 & 9.79 & 8.82 & \\
\hline 2.27 & 8.91 & 2.114 & 0.98 & -18.86 & 8.69 & 8.80 & \\
\hline \multicolumn{8}{|c|}{ (C) High growth rates } \\
\hline 10.27 & 8.11 & 2.01 & 1.40 & -35.14 & 18.36 & 11.00 & Laws et al. (1997) ${ }^{\circ}$ \\
\hline 0.64 & 8.94 & 1.39 & 1.38 & -16.15 & 7.42 & 4.95 & \\
\hline 11.70 & 8.20 & $\sim 1.89$ & 1.41 & -21.10 & 12.40 & - & Johnston $(1996)^{~}{ }^{\circ}$ \\
\hline 37.69 & 7.82 & 2.060 & 1.63 & -26.58 & 16.68 & 10.03 & Burkhardt et al. (1999a) *. \\
\hline 14.48 & 8.24 & 2.066 & 1.39 & -25.58 & 15.64 & 9.90 & \\
\hline 7.22 & 8.59 & 2.079 & 1.41 & -24.48 & 14.49 & 9.24 & \\
\hline 4.36 & 8.76 & 2.078 & 1.64 & -22.69 & 12.64 & 8.40 & \\
\hline 3.21 & 8.89 & 2.064 & 1.63 & -26.91 & 17.03 & 8.68 & \\
\hline 2.10 & 9.02 & 2.066 & 1.64 & -20.76 & 10.64 & 9.01 & \\
\hline
\end{tabular}

Table 2. As in Table 1 except for results obtained at growth rates outside the defined ranges of Categories $\mathrm{A}$ to $\mathrm{C}$

\begin{tabular}{|c|c|c|c|c|c|c|c|}
\hline $\begin{array}{c}{\left[\mathrm{CO}_{2} \mathrm{aq}\right]} \\
\left(\mu \mathrm{mol} \mathrm{kg}^{-1}\right)\end{array}$ & $\mathrm{pH}$ & $\begin{array}{c}\text { DIC } \\
\left(\mathrm{mmol} \mathrm{kg}^{-1}\right)\end{array}$ & $\begin{array}{c}\mu_{\mathrm{i}} \\
\left(\mathrm{d}^{-1}\right)\end{array}$ & $\begin{array}{c}\delta^{13} \mathrm{Cp}_{\mathrm{p}} \\
(\%)\end{array}$ & $\begin{array}{c}\varepsilon_{\mathrm{p}} \\
(\%)\end{array}$ & $\begin{array}{c}\mathrm{C} / \mathrm{cell} \\
\left(\mathrm{pg} \text { cell }{ }^{-1}\right)\end{array}$ & Source \\
\hline \multicolumn{8}{|c|}{ (A) Low growth rates } \\
\hline 11.70 & 8.20 & $\sim 1.89$ & 0.29 & -24.80 & 16.14 & - & Johnston (1996) ". \\
\hline 0.23 & 9.58 & 2.199 & 0.34 & -11.52 & 0.98 & 14.17 & This study $\cdot$ \\
\hline \multicolumn{8}{|c|}{ (B) Intermediate growth rates } \\
\hline 15.61 & 7.97 & 2.10 & 0.75 & -41.88 & 22.04 & 8.20 & Laws et al. (1997) ${ }^{\circ}$ \\
\hline 10.72 & 8.10 & 202 & 1.25 & -35.82 & 18.94 & 9.15 & \\
\hline 2.93 & 8.51 & 1.68 & 0.75 & -26.79 & 16.76 & 6.21 & \\
\hline 2.36 & 8.58 & 1.67 & 0.75 & -21.09 & 11.83 & 6.99 & \\
\hline 30.21 & 7.90 & 2.084 & 1.19 & -26.31 & 16.22 & 15.86 & This study. \\
\hline 7.59 & 8.47 & 2081 & 1.18 & -24.83 & 14.67 & 15.07 & \\
\hline 6.69 & 8.51 & 2.060 & 1.26 & -24.95 & 14.80 & 12.41 & \\
\hline 1.16 & 9.12 & 2.066 & 1.33 & -17.64 & 7.24 & 12.97 & \\
\hline \multicolumn{8}{|c|}{ (C) High growth rates } \\
\hline 11.70 & 8.20 & -1.89 & 1.97 & -21.20 & 12.30 & - & Johnston (19yo) ${ }^{.}$ \\
\hline 37.69 & 7.82 & 2.060 & 2.27 & -25.92 & 15.99 & 9.70 & Burkhardt et al. (1999a) * \\
\hline 14.48 & 8.24 & 2.066 & 2.30 & -25.65 & 15.70 & 9.57 & \\
\hline 7.22 & 8.59 & 2.079 & 2.21 & -25.51 & 15.57 & 8.91 & \\
\hline 4.36 & 8.76 & 2.078 & 2.21 & -23.96 & 13.95 & 8.07 & \\
\hline 3.21 & 8.89 & 2.064 & 2.23 & -21.71 & 11.62 & 8.35 & \\
\hline 2.10 & 9.02 & 2.066 & 2.21 & -19.58 & 9.42 & 8.68 & \\
\hline
\end{tabular}



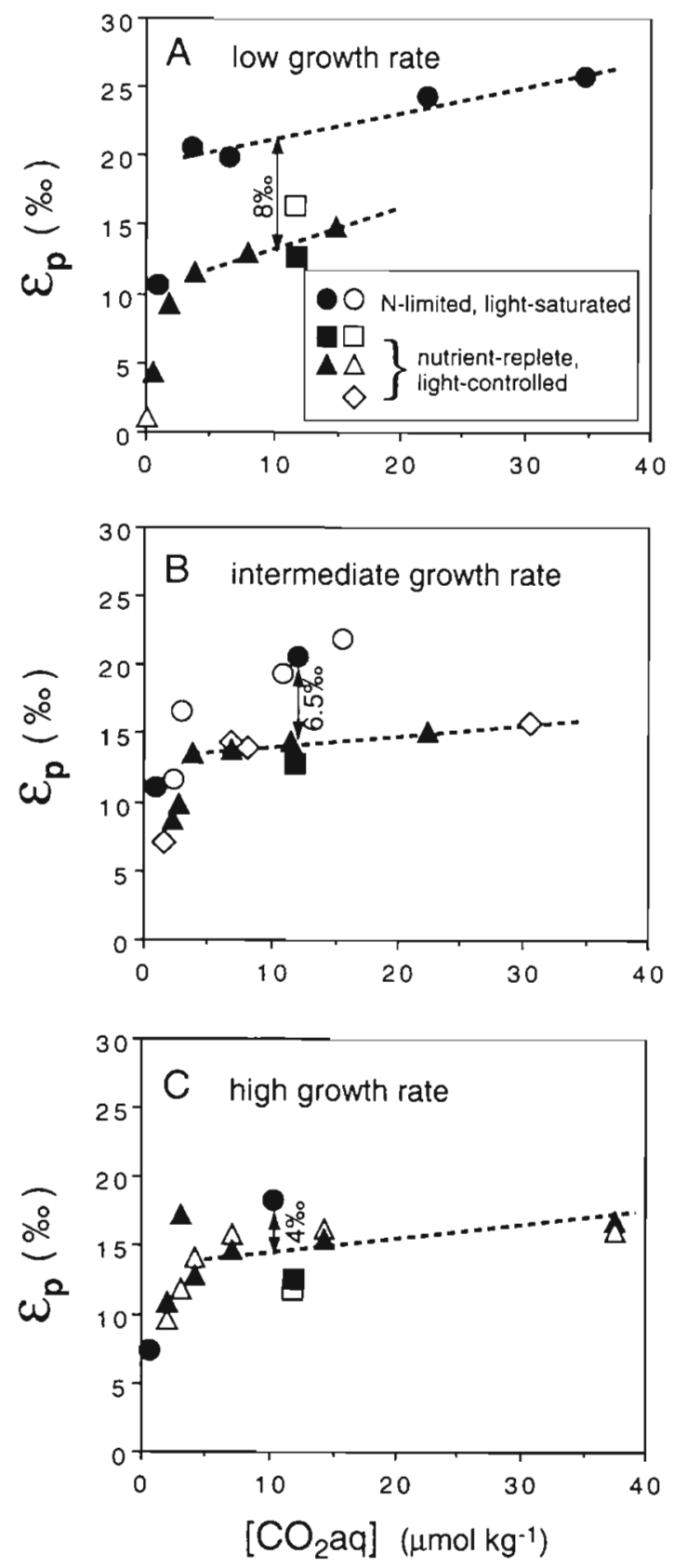

Fig. 1. Carbon isotope fractionation, $\varepsilon_{\mathrm{p}}$ in relation to $\mathrm{CO}_{2}$ concentration, $\left[\mathrm{CO}_{2} \mathrm{aq}\right]$, for Phaeodactylum tricornutum in 3 growth rate categories: (A) low growth rate, $\mu_{1}=0.5 \mathrm{~d}^{-1} \pm 10 \%$ (B) intermediate growth rate, $\mu_{1}=1.0 \mathrm{~d}^{-1} \pm 10 \%$; (C) high growth rate, $\mu_{\mathrm{i}}=1.5 \mathrm{~d}^{-1} \pm 10 \%$ (compare Table 1 ). Data were obtained in $\mathrm{N}$-limited, light-saturated chemostat cultures by Laws et al. (1997) (circles), and in nutrient-replete, lightcontrolled batch culture incubations by Johnston (1996) (squares), Burkhardt et al. (1999a) (triangles in C), and this study (triangles in $\mathrm{A}$ and $\mathrm{B}$, diamonds). Culture experiments used 2 different strains of $P$. tricornutum, clone CCMP 1327 (circles and diamonds) and CCAP 1052/1A (squares and triangles). Dashed lines represent linear regressions for data at $\left[\mathrm{CO}_{2} \mathrm{aq}\right]>3.5 \mu \mathrm{mol} \mathrm{kg}{ }^{-1}$. Open symbols represent data outside the range of growth rates in Categories $A$ to $C$ (compare

Table 2) and are not included in linear regressions
As indicated in Table 1, the carbon contents per cell differ noticeably within and between data sets and are considerably higher under low $\mu$ in this study. If $\mu_{\mathrm{i}}$ were expressed on a carbon content per cell basis, values in the low $\mu_{i}$ category of our study would be somewhat higher than those calculated from changes in cell concentration. However, since $\varepsilon_{\mathrm{p}}$ was insensitive to changes in $\mu_{1}$ in light-controlled batch cultures (see below), a correction for the observed differences in cellular carbon contents was not critical to the interpretation of the results. In this context it is worth noting that differences in cellular carbon contents between the 2 strains of Phaeodactylum tricornutum, CCAP 1052/1A and CCMP 1327, had no detectable effect on $\varepsilon_{p}$. Despite a factor of almost 2 difference in $C$ content between the 2 clones, $\varepsilon_{\mathrm{p}}$ values are practically identical when grown under the same conditions in batch culture incubations (Fig. 1B, compare triangles and diamonds).

Results and discussion. Isotope fractionation in relation to growth rate and $\mathrm{CO}_{2}$ concentration: A close agreement is obtained between all data sets with respect to the general trend of $\varepsilon_{\mathrm{p}}$ versus $\left[\mathrm{CO}_{2} \mathrm{aq}\right]$ (Fig. 1). In the range of $\left[\mathrm{CO}_{2} \mathrm{aq}\right]$ naturally occurring in the ocean (ca 8 to $25 \mu \mathrm{mol} \mathrm{kg}^{-1}$ ), $\varepsilon_{\mathrm{p}}$ of Phaeodactylum tricornutum shows a relatively small $\mathrm{CO}_{2}$ dependence, increasing by 2 to $3 \%$ with [ $\mathrm{CO}_{2} \mathrm{aq}$ ] increasing from 5

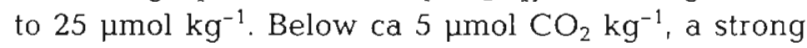
decline in $\varepsilon_{\mathrm{p}}$ with decreasing $\left[\mathrm{CO}_{2} \mathrm{aq}\right]$ is observed. This trend is consistently found in each of the $3 \mu_{\mathrm{i}}$ categories in light-controlled batch cultures and is clearly indicated also for nitrate-limited chemostats at low $\mu_{i}$ (Fig. 1A). Although the limited number of data points from chemostat experiments precludes determining the relationship of $\varepsilon_{\mathrm{p}}$ versus $\left[\mathrm{CO}_{2} \mathrm{aq}\right]$ at intermediate and high $\mu_{\mathrm{i}}$ (Fig. 1B,C), the available data indicate that the trend observed at low $\mu_{1}$ (Fig. 1A) may also hold true at higher growth rates. This interpretation is further supported when data outside the narrow range of growth rates selected in the 3 categories are included (open symbols in Fig. 1).

With respect to the absolute values of $\varepsilon_{\mathrm{p}}$, reasonable agreement is further obtained between the results of Johnston (1996), Burkhardt et al. (1999a), and the present study (Fig. 1). As the data of Johnston (1996) correspond to only a single [ $\left.\mathrm{CO}_{2} \mathrm{aq}\right]$ in each $\mu_{1}$ category, they do not provide information on the $\mathrm{CO}_{2}$ dependence of $\varepsilon_{\mathrm{p}}$. However, they support the finding that changes in $\mu_{\mathrm{i}}$ in response to changing PFD have little or no effect on isotope fractionation in Phaeodactylum tricornutum (with the exception of 1 high $\varepsilon_{\mathrm{p}}$ value at PFD $<10 \mu \mathrm{mol} \mathrm{m} \mathrm{m}^{-2} \mathrm{~s}^{-1}$, see Fig. 3A in Johnston 1996). Close agreement in $\varepsilon_{\mathrm{p}}$ responses is also obtained between the 2 strains of $P$. tricornutum, clone CCAP 1052/1A and CCMP 1327, used in our study (Fig. 1B, 
triangles and diamonds, respectively). This shows that possible strain-specific differences in isotope fractionation between these 2 clones - if present - are much smaller than differences obtained in response to different experimental conditions.

Strong differences in the absolute values of $\varepsilon_{\mathrm{p}}$ evidently exist between results obtained under nitratecontrolled (Laws et al. 1995, 1997) and light-controlled growth (Johnston 1996, Burkhardt et al. 1999a, this study). $\varepsilon_{\mathrm{p}}$ values are considerably higher in $\mathrm{N}$-limited cultures at all $\mu_{\mathrm{i}}$ under similar $\left[\mathrm{CO}_{2} \mathrm{aq}\right]$ (Fig. 1). In addition, whereas a 3 -fold increase in $\mu_{1}$ due to increasing PFD has virtually no effect on $\varepsilon_{p}$ a similar increase in $\mu_{1}$ due to enhanced nitrate supply results in significantly lower $\varepsilon_{\mathrm{p}}$ values. This causes the offset in $\varepsilon_{\mathrm{p}}$ between nitrate- and light-controlled cultures to drop from $8 \%$ at low $\mu_{i}$ to $4 \%$ at high $\mu_{1}$ (Fig. 1). How can apparent differences in $\varepsilon_{p}$ between $N$ - and light-controlled incubations be reconciled with our present understanding of the basic mechanisms regulating isotope fractionation?

Mechanisms of isotope fractionation: The key variables determining carbon isotope fractionation in photosynthetic carbon fixation are: (1) the inorganic carbon source entering the cell, i.e. $\mathrm{CO}_{2}$ or $\mathrm{HCO}_{3}{ }^{-}$, which differ in their isotopic composition by ca 8 to $10 \%$, and (2) the ratio of $\mathrm{CO}_{2}$ leakage out of the cell (efflux) to carbon flux into the cell (influx).

A lower proportion of $\mathrm{HCO}_{3}{ }^{-}$relative to $\mathrm{CO}_{2}$ uptake could account for the high $\varepsilon_{\mathrm{p}}$ values in $\mathrm{N}$-limited compared to light-controlled cultures (Fig, 1). Reduced $\mathrm{HCO}_{3}^{-}$utilisation may be caused, for example, by reduced synthesis of transport proteins for $\mathrm{HCO}_{3}^{-}$ uptake in $\mathrm{N}$-limited cells. Explaining up to $8 \%$ higher $\varepsilon_{\mathrm{p}}$ values by reduced $\mathrm{HCO}_{3}{ }^{-}$utilisation (Fig. $1 \mathrm{~A}$ ) would imply that the ratio of carbon efflux to influx remains approximately constant. With a reduction in $\mathrm{HCO}_{3}^{-}$ uptake this would require that $\mathrm{CO}_{2}$ uptake increases proportionally. Support for this mechanism could be gained if a stronger reliance on $\mathrm{CO}_{2}$ in $\mathrm{N}$-limited cultures would be reflected in a stronger $\mathrm{CO}_{2}$ dependence of $\varepsilon_{\mathrm{p}}$. This is not substantiated by the data comparison An equally low dependence of $\varepsilon_{\mathrm{p}}$ on $\mathrm{CO}_{2}$ at concentra

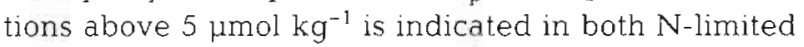
and light-controlled Phaeodactylum tricornutum.

Alternatively, the observed differences in $\varepsilon_{p}$ could be explained by differences in the efflux to influx ratio without invoking a difference in the source of inorganic carbon. The hicher the ratio of efflux to influx, the stronger the discrimination against. ${ }^{13} \mathrm{C}$ (Sharkey \& Berry 1985), in the extreme case up to the kinetic fractionation of the carboxylating enzymes ( 25 to $27 \%$ for the dominating carboxylase RUBISCO). Carbon influx is the sum of $\mathrm{CO}_{2}$ diffusive transport into the cell and active uptake of $\mathrm{CO}_{2}$ and/or $\mathrm{HCO}_{3}{ }^{-}$. For a given cellu- lar carbon content, the rate of carbon fixation is a direct function of $\mu_{\mathrm{i}}$. Thus, an increase in $\mu_{1}$ at constant influx reduces carbon efflux and lowers discrimination against ${ }^{13} \mathrm{C}$, i.e. decreases $\varepsilon_{\mathrm{p}}$. The observed lack of a response of $\varepsilon_{\mathrm{p}}$ to a 3 -fold increase in $\mu_{\mathrm{i}}$ in light-controlled Phaeodactylum tricornutum (Fig. 1) implies that carbon influx increased with increasing $\mu_{i}$. In fact, constant $\varepsilon_{\mathrm{p}}$ at increasing $\mu_{\mathrm{i}}$ can only be explained if carbon influx increased sufficiently to keep the ratio of influx to fixation constant. While enhanced carbon influx could be due to an increase in the permeability of the cell membrane for $\mathrm{CO}_{2}$ and/or to active carbon uptake, the presence of a highly efficient carbon concentrating mechanism in Phaeodactylum tricornutum (Patel \& Merret 1986, Burns \& Beardall 1987, Rotatore et al. 1995 ) stresses the importance of the latter mechanism in the regulation of carbon influx. In contrast, rising $\mu_{2}$ in response to increasing $N$ supply led to a decrease in $\varepsilon_{\mathrm{p}}$, suggesting that carbon uptake in $\mathrm{N}$-limited cultures was not as tightly coupled to carbon fixation as in lightcontrolled incubations.

These observations indicate a principal difference in the regulation of carbon acquisition for different growth-rate-limiting resources. Evidently, changes in $N$ supply and PFD causing identical changes in $\mu$ can have very different effects on active carbon uptake. This may be understood when considering the relevant cellular processes affected by different limiting resources. In the following we will therefore briefly outline some of the photochemical constraints which may be of relevance to the regulation of active carbon uptake.

Photochemical constraints: During photosynthetic growth, $\mathrm{CO}_{2}$ and other nutrients are reduced and transformed into new cell biomass. The entire process consumes electrons (NADPH) and ATP, which are ultimately generated by the photochemical reactions. For any given composition of biomass at steady-state growth, ATP and NADPH must be delivered in a ratio (ATP/e $)^{-}$) which matches the requirement to synthesize biomass. Any other process, such as active carbon uptake, will enhance the ATP/e- ratio that must be met by the photochemical reactions. Vice versa, if the photochemical reactions yield higher ATP/e ratios, the ATP in excess of what is minimally required to synthesize the biomass might be used for active uptake.

The ATP/e ratio is determined by both linear (noncyclic) and non-linear (cyclic) electron flow during photosynthesis. Linear electron flow refers to the direct transfer of electrons from water to ferredoxin and NADPH as terminal electron acceptors in a reaction sequence mediated by photosystems PSII and PSI. While the ATP/e ratio might vary during linear electron flow due to the involvement of the Q-cycle (re-oxidation of reduced plastochinone through the 
cytochrome b6f complex), it increases significantly during non-linear electron flow. Non-linear flow involves cyclic PSI transport (electron transfer from ferredoxin to the plastochinone pool) and the Mehler reaction felectron flow through both photosystems with subsequent reduction of as much $\mathrm{O}_{2}$ as is generated by the oxidation of water). An increase in the proportion of non-linear to linear electron transport increases the $\mathrm{ATP} / \mathrm{e}^{-}$ratio and thus the amount of chemical energy available for processes such as active carbon transport.

The relative contribution of non-linear electron flow to steady-state photosynthesis and its regulation under variable environmental conditions is poorly quantified. Clearly, one major site for regulation is the electron transfer from ferredoxin to competing pathways. There, cyclic PSI transport and the Mehler reaction compete directly with other electron transfer pathways, most prominently the reduction of NADP (required in the photosynthetic carbon reduction cycle and in the reduction of nitrate to nitrite) and the reduction of nitrite reductase (catalyzing the reduction of nitrite to ammonia). The critical question is: How would the proportion of non-linear to linear electron transport be affected by differences in the growthrate-limiting resource?

Nitrate-versus light-controlled growth: Nitrate-limiting conditions at high PFD can be expected to affect the photochemical electron transport in 2 ways: (1) The limited rate of nitrate supply keeps the electron demand for the reduction of nitrate to ammonium low compared to nitrate-replete conditions at similar PFD. This would raise the relative strength of competing electron acceptors favoring the rate of non-linear electron flow. (2) Reduced protein synthesis under N-limiting conditions is likely to be reflected in the cellular activity of the carboxylating enzyme RUBISCO, but may also affect the ability of cells to harvest light efficiently or to synthesize transport proteins involved in carbon uptake. In analogy to nitrate reduction, a decrease in electron demand for photosynthetic $\mathrm{CO}_{2}$ reduction due to repressed synthesis of RUBISCO would favor competing reactions such as cyclic PSI transport or the Mehler reaction. In this scenario, ferredoxin can be regarded as a controller for the transfer of electrons at branching pathways.

In contrast to $\mathrm{N}$-limited growth, the primary effect of light limitation on photosynthesis is the low rate of photon flux to the reaction center of PSII. At this acceptor site for electrons, however, no competing reactions exist which could provide a similar regulatory mechanism as described above. A decline in PFD under nutrient-replete conditions would therefore lower the total rate of electron flow through both PSII and PSI without having a significant effect on the ATP/ $\mathrm{e}^{-}$ratio. At a given $\mu_{\mathrm{i}}$, higher values of $\varepsilon_{\mathrm{p}}$ in $N$-limited chemostats compared to light-controlled cultures may then simply reflect higher rates of active carbon uptake, fueled by elevated $\mathrm{ATP} / \mathrm{e}^{-}$ratios.

Other environmental variables: If indeed the ATP/eratio is a key variable in determining active carbon uptake and, hence, $\varepsilon_{\mathrm{p}}$, then any environmental variable influencing this ratio would potentially affect $\varepsilon_{\mathrm{p}}$. A change in the ATP/e $\mathrm{e}^{-}$ratio, for instance, may occur in response to a shift in the nitrogen source (i.e. between $\mathrm{NO}_{3}{ }^{-}$and $\mathrm{NH}_{4}$ ). Whereas ammonium can be directly utilized by the cell since it is the form of nitrogen used in amino acid synthesis, the reduction of 1 molecule of nitrate to ammonium requires 8 electrons. Shifting from nitrate to ammonium as the external nitrogen source would eliminate this electron sink and favor competing reactions such as non-linear electron transport and/or $\mathrm{CO}_{2}$ reduction in the Calvin cycle. In case of increased non-linear electron transport, the resulting higher $\mathrm{ATP} / \mathrm{e}^{-}$ratio could support enhanced active carbon uptake, thus leading to increased $\varepsilon_{\mathrm{p}}$. If the 'extra' electrons are primarily channeled into $\mathrm{CO}_{2}$ reduction in the Calvin cycle, the resulting higher carbon demand would lower ${ }^{13} \mathrm{C}$ discrimination. Reduced ${ }^{13} \mathrm{C}$ discrimination following ammonium spiking of diatom-dominated natural phytoplankton was in fact reported by Dehairs et al. (1997). While these authors suggest that a shift from Calvin cycle carboxylation to $\beta$-carboxylation may have led to the observed response, reduced ${ }^{13} \mathrm{C}$ discrimination would also be consistent with enhanced $\mathrm{CO}_{2}$ reduction.

Differences in the $\mathrm{ATP} / \mathrm{e}^{-}$ratio may also arise depending on the growth-limiting nutrients (e.g. $\mathrm{N}$ vs $\mathrm{P}$ or $\mathrm{Fe}$ ). Phosphorus limitation can affect photosynthetic energy conversion by reducing the rate of protein synthesis in the photosynthetic apparatus. In addition, $P$ limitation lowers the rate of synthesis and regeneration of substrates in the Calvin cycle, thereby reducing the rate of light utilization for carbon fixation (Falkowski \& Raven 1997). Iron limitation, on the other hand, leads to a loss of PSI and PSII reaction centers, without a corresponding loss of the antenna pigments. Reduced coupling of light harvesting to electron transport in Fe-limited cells drastically lowers the quantum yield of photochemistry (Geider \& LaRoche 1994). Although it is not clear what effects $\mathrm{P}$ and Fe limitation would have on the ATP/ $\mathrm{e}^{-}$ratio, one might speculate that they may differ from each other as well as from the effect of $\mathrm{N}$ limitation.

Conclusions. Whether or not the above scenario adequately describes the origin of the observed differences in carbon isotope fractionation of nitrate- and light-controlled cultures of Phaeodactylum tricornutum, the results of this comparison reveal additional uncertainty in the interpretation of carbon isotope data. In addition to growth rate and $\mathrm{CO}_{2}$ concentration, 
carbon isotope fractionation may be affected by the growth-limiting resource. Thus, even if species-specific factors determining isotope fractionation, such as cell size, carbon acquisition pathways, composition and ${ }^{13} \mathrm{C}$ discrimination of the carboxylating enzymes can be accounted for, attempts to reconstruct growth rate or $\mathrm{CO}_{2}$ concentration from organic matter carbon isotope composition may critically depend on knowledge of the growth-limiting resource at the time of organic matter production. Clearly, a better understanding of the factors determining active carbon uptake, both under controlled laboratory conditions and in the field, would improve our ability to interpret carbon isotope fractionation in marine phytoplankton.

Acknowledgements. We thank C. Hartmann, A. Mackensen, K.-U. Richter, G. Traue, and I. Zondervan for technical support and $M$. Botros for critically reading the manuscript. We thank E. Laws and B. Popp for providing us with Phaeodactylum tricornutum, clone CCMP 1327. This research was conducted as part of a German-Israeli Cooperation in Marine Sciences (MARS 2) under coordination of the GKSS funded by the Bundesministerium für Bildung und Forschung (BMBF), contract number 03F0200A.

\section{LITERATURE CITED}

Almgren T, Dyrssen D, Fonselius S (1988) Determination of alkalinity and total carbonate. In: Grasshoff $\mathrm{K}$, Ehrhardt $M$, Kremling $K$ (eds) Methods of seawater analysis. Verlag Chemie, Weinheim, p 99-123

Arthur MA, Dean WE, Claypool GE (1985) Anomalous ${ }^{13} \mathrm{C}$ enrichment in modern marine organic carbon. Nature 315 : 216-218

Bidigare RR, Fluegge A, Freeman KH, Hanson KL, Hayes JM, Hollander D, Jasper JD, King LL, Laws LA, Milder J, Millero FJ, Pancost R, Popp BN, Steinberg PA, Wakeham $S G$ (1997) Consistent fractionation of ${ }^{13} \mathrm{C}$ in nature and in the laboratory: growth-rate effects in some haptophyte algae. Global Biogeochem Cycles 11:279-292

Burkhardt S, Riebesell U, Zondervan I (1999a) Effects of growth rate, $\mathrm{CO}_{2}$ concentration, and cell size on the stable carbon isotope fractionation in marine phytoplankton. Geochim Cosmochim Acta 63:3729-3741

Burkhardt S, Riebesell U, Zondervan I (1999b) Stable carbon 1sotope fractionation by marine phytoplankton in response to daylength, growth rate, and $\mathrm{CO}_{2}$ availability. Mar Ecol Prog Ser 184:31-41

Burns BD, Beardall J (1987) Utilization of inorganic carbon by marine microalgae. J Exp Mar Ecol 107:75-86

Degens ET, Guiliard RR, Sackett WM, Hellebust JA (1968) Metabolic fractionation of carbon isotopes in marine plankton-I. Temperature and respiration experiments. Deep-Sea Res 15:1-9

Dehairs F, Konczyncka F. Nielcen P. T.ancelnt C. Bakker DCE. Koeve W, Goyens L (1997) $\delta^{13} \mathrm{C}$ of Southern Ocean organic matter during spring and austral early summer: regional and temporal variability. Deep-Sea Res II 44:129-142

Deuser WG, Degens ET, Guillard RRL. (1968) Carbon isotope relationships between plankton and sea water. Geochim Cosmochim Acta 32:657-660

Edler L (1979) Recommendations for marine biological studies in the Baltic Sea. Phytoplankton and chlorophyll. Baltic Mar Biol Publ 5:1-38

Falkowski PG, Raven JA (1997) Aquatic photosynthesis. Blackwell, Oxford

Fogel ML, Cifuentes LA, Velinsky DJ, Sharp JH (1992) Relationship of carbon availability in estuarine phytoplankton to isotopic composition. Mar Ecol Prog Ser 82:291-300

Francois R, Altabet MA, Goericke R, McCorkle DC, Brunet C, Poisson $\mathrm{A}$ (1993) Changes in the $\delta^{13} \mathrm{C}$ of surface water particulate organic matter across the subtropical convergence in the SW Indian Ocean. Global Biogeochem Cycles 7 : $627-644$

Freeman KH, Hayes JM (1992) Fractionation of carbon isotopes by phytoplankton and estimates of ancient $\mathrm{CO}_{2}$ levels. Global Biogeochem Cycles 6:185-198

Geider RJ, LaRoche J (1994) The role of iron in phytoplankton photosynthesis, and the potential for iron-limitation of primary production in the sea. Photosynth Res 39:275-301

Goericke R, Montoya JP. Fry B (1994) Physiology of isotope fractionation in algae and cyanobacteria. In: Lajtha $\mathrm{K}$. Michener RH (eds) Stable isotopes in ecology and environmental science. Blackwell Scientific Publications, Oxford, p 187-221

Goyet C, Poisson A (1989) New determination of carbonic acid dissociation constants in seawater as a function of temperature and salinity. Deep-Sea Res 36(11):1635-1654

Guillard RLL, Ryther JH (1962) Studies of marine planktonic diatoms I. Cyclotella nana HUSTEDT and Detonula confervacea (CLEVE) GRAN. Can J Microbiol 8:229-231

Hinga KR, Arthur MA, Pilson MEQ. Whitaker D (1994) Carbon isotope fractionation by marine phytoplankton in culture: the effects of $\mathrm{CO}_{2}$ concentration, $\mathrm{pH}$, temperature, and species. Global Biogeochem Cycles 8:91-102

Hobbie, JE, Daley RJ, Jasper S (1977) Use of Nuclepore filters for counting bacteria by fluorescence microscopy. Appl Environ Microbiol 33:1225-1228

Jasper JP, Hayes JM, Mix AC, Prahl FG (1994) Photosynthetic fractionation of ${ }^{13} \mathrm{C}$ and concentrations of dissolved $\mathrm{CO}_{2}$ in the central equatorial Pacific during the last 255,000 years. Paleoceanography 9:781-798

Johnson KM, Sieburth JMCN, Williams PJleB, Brändström L (1987) Coulometric total carbon dioxide analysis for marine studies: automation and calibration. Mar Chem $21: 117-133$

Johnston AM (1996) The effect of environmental variables on ${ }^{13} \mathrm{C}$ discrimination by two marine phytoplankton. Mar Ecol Prog Ser 132:257-263

Korb RE, Raven JA, Johnston AM, Leftley JW (1996) Effects of cell size and specific growth rate on stable carbon isotope discrimination by two species of marine diatom. Mar Ecol Prog Ser 143:283-288

Laws EA, Bannister TT (1980) Nutrient- and light-limited growth of Thalassiosira fluviatilis in continuous culture, with implications for phytoplankton growth in the ocean. Limnol Oceanogr 25:457-473

Laws EA, Popp BN, Bidigare RR, Kennicutt MC, Macko SA. (1995) Dependence of phytoplankton carbon isotopic composition on growth rate and $\left[\mathrm{CO}_{2}\right]$ aq: theoretical considerations and experimental results. Geochim Cosmochim Acta 59:1131-1138

Laws EA, Popp BN, Bidigare RR (1997) Effect of growth rate and $\mathrm{CO}_{2}$ concentration on carbon isotopic fractionation by the marine diatom Phaeodactyium tricornutum. Limnol Oceanogr 42:1552-1560

Mackensen A, Hubberten HW, Scheele N, Schlitzer R (1996) Decoupling of $\delta^{13} \mathrm{C \Sigma CO}_{2}$ and phosphate in recent weddell Sea deep and bottom water: implications for glacial 
Southern Ocean paleoceanography. Paleoceanography 11: 203-215

Mizutani $\mathrm{H}$, Wada $\mathrm{E}$ (1982) Effect of high atmospheric $\mathrm{CO}_{2}$ concentration on $\delta^{13} \mathrm{C}$ of algae. Origins Life 12:377-390

Mook WG $(1986){ }^{13} \mathrm{C}$ in atmospheric $\mathrm{CO}_{2}$. Neth J Sea Res 20 : 211-223

Mook WG, Bommerson JC, Staverman WH (1974) Carbon isotope fractionation between dissolved bicarbonate and gaseous carbon dioxide. Earth Planet Sci Lett 22:169-176

Patel BN, Merret MJ (1986) Inorganic carbon uptake by the marine diatom Phaeodactylum tricornutum. Planta 169: $222-227$

Popp BN, Laws EA, Bidigare RR, Dore JE, Hanson KL, Wakeham SG (1998) Effect of phytoplankton cell geometry on carbon isotopic fractionation. Geochim Cosmochim Acta 62:69-77

Rau GH, Takahashi T, Des Marais DJ (1989) Latitudinal variations in plankton $\delta^{13} \mathrm{C}$ : implications for $\mathrm{CO}_{2}$ and productivity in past oceans. Nature 341:516-518

Editorial responsibility: Otto Kinne (Editor),

Oldendorf $/$ uhe, Germany
Rau GH, Riebesell U, Wolf-Gladrow D (1996) A model of photosynthetic ${ }^{13} \mathrm{C}$ fractionation by manine phytoplankton based on diffusive molecular $\mathrm{CO}_{2}$ uptake. Mar Ecol Prog Ser 133:275-285

Rotatore C, Colman B, Kuzma M (1995) The active uptake of carbon dioxide by the marine diatoms Phaeodactylum tricornutum and Cyclotella sp. Plant Cell Environ 18: $913-918$

Sharkey TD, Berry JA (1985) Carbon isotope fractionation of algae as influenced by an inducible $\mathrm{CO}_{2}$ concentrating mechanism. In: Lucas WJ, Berry JA (eds) Inorganic carbon uptake by aquatic photosynthetic organisms. The American Society of Plant Physiologists, Rockville, MD, p $389-401$

Thompson PA, Calvert SE (1994) Carbon isotope fractionation by a marine diatom: the influence of irradiance, daylength, $\mathrm{pH}$, and nitrogen source. Limnol Oceanogr 39:1835-1844 Thompson PA, Calvert SE (1995) Carbon isotope fractionation by Emiliania huxleyi. Limnol Oceanogr 40:673-679

Submitted: February 11, 1999; Accepted: January 7, 2000 Proofs received from author(s): February 9, 2000 